\title{
ANALISIS KANDUNGAN LOGAM TIMBAL PADA MINYAK SEBELUM DAN SESUDAH DIGUNAKAN PEDAGANG GORENGAN DI KELURAHAN BENOA
}

\author{
Raissa Lutfidiani, Made Ayu Hita Pretiwi Suryadhi* \\ Program Studi Kesehatan Masyarakat Fakultas Kedokteran Universitas Udayana \\ Alamat: Jalan PB. Sudirman Denpasar, Bali 80232
}

\begin{abstract}
ABSTRAK
Gorengan adalah jajanan yang sering dikonsumsi masyarakat karena selain harganya yang murah, enak, dan mudah didapat, gorengan juga dapat memberikan asupan energi di antara waktu makan. Pedagang gorengan yang biasanya terletak di pinggiran jalan dapat berisiko tercemar timbal pada minyak goreng yang digunakan yang berasal dari emisi asap kendaraan bermotor. Penelitian ini bertujuan untuk mengetahui kandungan $\mathrm{Pb}$ yang ada pada minyak goreng sebelum dan sesudah digunakan oleh pedagang gorengan di Kelurahan Benoa. Desain penelitian yang digunakan adalah penelitian survei deskriptif dan pengambilan sampel pada penelitian ini menggunakan teknik purposive sampling. Pada tiap pedagang akan diuji minyak sebelum dilakukan penggorengan, minyak sesudah penggorengan hari Jumat dan hari Sabtu, minyak setelah penggorengan tanpa bahan untuk membuat gorengan terakhir kali, dan gorengannya. Pemeriksaan laboratorium menggunakan metode Spektrofotometri Serapan Atom (SSA). Hasil laboratorium menunjukkan konsentrasi logam berat timbal (Pb) yang terdapat pada seluruh jenis minyak telah melebihi batas maksimum logam $\mathrm{Pb}$ pada minyak yang diatur dalam SNI 7387:2009. Sedangkan konsentrasi $\mathrm{Pb}$ yang terdapat pada gorengan tidak melebihi batas maksimum $\mathrm{Pb}$ yang diatur dalam Peraturan BPOM RI Nomor HK.00.06.1.52.4011.
\end{abstract}

Kata Kunci: Timbal, Minyak Goreng, Gorengan

\begin{abstract}
Fried foods are snacks that are often consumed by society because in addition to being cheap, delicious, and easy to get, fried foods can also provide energy intake between meals. Fried food merchants who are usually located on the side of the road could risk of being contaminated with lead in the cooking oil used from motor vehicle fumes emissions. This research aims to determine the lead content in cooking oil before and after being used by fried food merchants in Benoa Village. The research design used is a descriptive survey research and sampling on this study used a purposive sampling technique. Each merchant will be tested of cooking oil before fried, cooking oil after fried on Friday and Saturday, cooking oil after fried without ingredients to make the last fry, and the fried food. A laboratory examination used the Atomic Absorption Spectrophotometry (AAS). Laboratory results showed the concentration of heavy metal lead $(\mathrm{Pb})$ contained in all types of oil has exceeded the maximum metallic $\mathrm{Pb}$ limit in the oil regulated in SNI 7387:2009. While the concentration of Pb contained in fried does not exceed the maximum $\mathrm{Pb}$ limit as regulated in BPOM RI Regulation Number HK.00.06.1.52.4011.
\end{abstract}

Keywords: Lead, Cooking Oil, Fried Food

\section{PENDAHULUAN}

Makanan adalah salah satu bagian yang penting untuk kesehatan dan kebutuhan manusia. Fungsi makanan sangat penting sebagai sumber tenaga, pertumbuhan tubuh, serta melindungi tubuh dari penyakit. Berdasarkan jenisnya, makanan terdiri dari dua macam yaitu makanan utama dan makanan ringan (snack). Makanan utama adalah makanan yang biasa dikonsumsi sehari-hari, diantaranya makanan pokok, lauk pauk, dan sayuran. Sedangkan makanan ringan adalah makanan yang dikonsumsi di luar makanan utama. Salah satu makanan ringan yang banyak digemari masyarakat Indonesia dari berbagai kalangan yaitu gorengan. Alasan gorengan sering dikonsumsi masyarakat karena selain harganya yang murah, mudah didapat, dan enak, gorengan juga dapat memberikan asupan energi di antara waktu makan.

Gorengan memiliki berbagai macam jenis, yaitu pisang goreng, bakwan, tahu isi, ubi goreng, dan lain-lain. Cara pengolahan gorengan seperti namanya yang berasal dari kata "goreng", makanan 
ini diolah dengan cara digoreng. Minyak goreng adalah bahan yang digunakan untuk menggoreng berbagai macam gorengan tersebut. Komposisi utama dari minyak goreng adalah trigliserida dengan atau tanpa perubahan kimiawi. Minyak goreng umumnya terbuat dari tumbuhan seperti kelapa, kelapa sawit, kacangkacangan, kanola, dan jagung. Sebagian kecil minyak goreng akan terabsorpsi atau diserap oleh bahan pangan yang digoreng sehingga memberikan rasa gurih, tekstur permukaan yang kering, serta kenampakan bahan pangan menjadi lebih menarik (Ariani, Yanti and Saputri, 2017).

Pedagang gorengan yang biasanya terletak di pinggiran jalan dapat berisiko tercemar timbal pada minyak goreng yang digunakan. Asap kendaraan yang mengandung bahan tambahan timbal $(\mathrm{Pb})$ dapat menghasilkan emisi timbal anorganik. Logam timbal yang bercampur dengan bahan bakar, selanjutnya akan bercampur dengan oli. Setelah melalui proses yang terjadi di dalam kendaraan, logam timbal akan keluar dari knalpot bersama dengan gas buangan lainnya, seperti $\mathrm{CO}_{2}, \mathrm{CO}, \mathrm{NO}, \mathrm{NO}_{2}, \mathrm{HC}, \mathrm{SO}_{2}$, dan partikel udara dalam wujud padat yang berdiameter kurang dari 10 mikrometer yang biasanya disebut dengan PM10 (particulate matter). Pencemaran dari emisi gas buangan kendaraan ini menyumbang sekitar $65 \%$ dari pencemaran udara, sehingga memperbesar kemungkinan masuknya cemaran udara ke tubuh konsumen melalui makanan (Alsuhendra and Ridawati, 2013).

Logam timbal ini ditambahkan dalam bentuk Tetra Ethyl Lead (TEL) ke dalam bensin untuk meningkatkan efisiensi pembakaran, meningkatkan daya pelumasan serta sebagai bahan aditif anti ketuk (anti-knock) pada bahan bakar yaitu untuk mengurangi hentakan dari kerja mesin sehingga kebisingan suara menurun saat pembakaran pada mesin kendaraan bermotor terjadi. Pada makhluk hidup, $\mathrm{Pb}$ dapat masuk ke dalam tubuh dan menyebabkan gangguan pada sistem hematopoetik, neurologis, ginjal, endokrin, hematologi, gastrointestinal, dan juga reproduksi. Pada anak-anak, timbal dapat menurunkan tingkat kecerdasan, pertumbuhan dan pendengaran, anemia, gangguan pemusatan perhatian, gangguan tingkah laku, kerusakan parah pada otak atau kematian (Perdana, Sy and Yerizel, 2017).

Menteri Lingkungan Hidup sejak 2006 sebenarnya sudah menetapkan aturan bahwa tidak menggunakan Tetra Ethyl Lead dalam pengolahan bensin. Namun pada penelitian yang dilakukan oleh Nyoman Sudarma (2020), dari hasil pengukuran kadar timbal dalam darah para pekerja di Terminal Ubung Denpasar didapatkan 4 dari 10 orang dengan kadar timbal tidak normal dengan kadar timbal tertinggi yaitu 0,48 ppm (Sudarma, 2020). Kadar timbal tersebut sudah melebihi ambang batas menurut keputusan Menteri Kesehatan Republik Indonesia Nomor 1406/MENKES/SK/XI/2002 yaitu 0,1-0,25 ppm (Menteri Kesehatan Republik Indonesia, 2002). Sedangkan pada penelitian Bella dan Erlani (2020), dari hasil analisis kandungan timbal pada jajanan gorengan di Kota Makassar didapatkan bahwa gorengan jenis bakwan memiliki kandungan timbal sebanyak 6,3397 mg/kg dan gorengan jenis pisang goreng dengan 
kandungan timbal sebanyak 8,7637 mg/kg. Hasil analisis tersebut tidak memenuhi syarat berdasarkan BPOM RI Nomor HK.00.06.1.52.4011 yaitu 0,25 mg/kg. Kandungan timbal tersebut disebabkan oleh pencemaran udara berupa gas emisi buangan kendaraan bermotor, peralatan dapur, kertas kemasan dan non kemasan, bahan yang digunakan, serta minyak goreng yang dipakai (Bella and Erlani, 2020).

Kandungan timbal juga ditemukan pada minyak sebelum dan sesudah penggorengan yang digunakan oleh pedagang gorengan di pinggir jalan R.E Martadinata Kelurahan Tondo Kota Palu. Hasil penelitian dari Ulandari, et al (2018) ini didapatkan bahwa semua sampel minyak sebelum penggorengan memenuhi syarat dengan hasil tertinggi 0,0771 ppm. Namun, pada sampel minyak sesudah penggorengan didapatkan 4 dari 5 sampel yang tidak memenuhi syarat peraturan BPOM RI Nomor HK.00.06.1.52.4011 tahun 2009 dengan hasil tertinggi yaitu 0,2562 ppm dimana kadar timbal tersebut sudah melebihi batas maksimum yaitu 0,1 ppm (Ulandari, Laenggeng and Rosnawati, 2018).

Perkembangan jumlah kendaraan bermotor di Indonesia makin bertambah seiring bertambahnya tahun. Total jumlah kendaraan bermotor di Indonesia pada tahun 2019 sebanyak 154.376 .369 unit. Kendaraan-kendaraan tersebut terdiri dari mobil penumpang, bus, truk, dan sepeda motor (Badan Pusat Statistik Indonesia, 2020). Bali sebagai salah satu provinsi yang sangat dikenal dengan pariwisatanya, dimana Kabupaten/Kota yang memiliki jumlah kendaraan bermotor terbesar di Bali diantaranya urutan pertama berada di Kota Denpasar sebanyak 1.420.997, kedua berada di Kabupaten Badung sebanyak 897.286, dan yang ketiga di Kabupaten Gianyar sebanyak 457.482 (Badan Pusat Statistik Provinsi Bali, 2020). Kabupaten Badung yang memiliki banyak tujuan wisata ini seperti pantai banyak dijumpai di Kecamatan Kuta Selatan. Kuta Selatan merupakan salah satu daerah yang memiliki berbagai hotel berbintang, sehingga banyak pendatang yang berasal dari luar Bali menjadi karyawan di hotel dan akhirnya menetap. Karena hal tersebut, jumlah kendaraan bermotor di Kuta Selatan juga lumayan banyak yaitu 12.826 unit. Kelurahan Benoa merupakan peringkat pertama dengan jumlah kendaraan bermotor terbanyak yaitu 7.440 unit (Badan Pusat Statistik Kabupaten Badung, 2020).

Dengan banyaknya kendaraan bermotor yang ada di Kelurahan Benoa, masih banyak pedagang gorengan dengan kuali atau wajan penggorengan tidak ditutupi dan juga tidak mengalami pergantian minyak goreng baru setelah menggunakan beberapa kali penggorengan, sehingga berpotensi tercemarnya atau masuknya timbal ke dalam minyak goreng yang digunakan. Berdasarkan latar belakang yang telah diuraikan sebelumnya, maka penulis tertarik melakukan penelitian untuk mengetahui kandungan logam berat timbal $(\mathrm{Pb})$ yang terdapat dalam minyak sebelum dan sesudah penggorengan yang digunakan pedagang gorengan di Kelurahan Benoa Provinsi Bali.

\section{METODE PENELITIAN}


Desain penelitian yang digunakan adalah penelitian survei deskriptif dan pengambilan sampel pada penelitian ini menggunakan teknik purposive sampling. Penelitian dilaksanakan selama bulan MeiJuni tahun 2021. Sampel yang akan digunakan dalam penelitian ini adalah minyak goreng dan gorengan yang berasal dari 5 pedagang gorengan. Pengambilan sampel bertujuan untuk diuji kandungan logam berat timbalnya dengan mengambil minyak sebelum, sesudah dilakukannya penggorengan, dan gorengan yang dijual. Kriteria inklusi dalam penelitian ini yaitu minyak goreng digunakan oleh pedagang gorengan yang berjarak $\leq 100$ meter dari traffic light, minyak goreng sebelum penggorengan belum dituangkan ke dalam wajan penggorengan, dan minyak goreng digunakan oleh pedagang gorengan pada hari Jumat dan Sabtu. Sedangkan kriteria eksklusi dalam penelitian ini adalah minyak goreng digunakan oleh pedagang gorengan yang berjarak >100 meter dari traffic light, minyak goreng sebelum penggorengan sudah dituangkan ke dalam kuali atau wajan penggorengan, dan minyak goreng digunakan oleh pedagang gorengan selain hari Jumat dan Sabtu. Hari yang ditentukan untuk pengambilan sampel minyak goreng adalah hari sibuk berdasarkan observasi awal peneliti yaitu pada hari Jumat dan pada hari libur yaitu hari Sabtu. Analisis kandungan logam berat timbal $(\mathrm{Pb})$ pada minyak goreng dan gorengan dilakukan dengan metode Spektrofotometri Serapan Atom (SSA). Tahap-tahap pelaksanaannya adalah:

1) Proses Destruksi Basah

a. Siapkan timbangan yang sudah dikalibrasi, gelas bekker yang sudah diberi label, gelas bekker tanpa label, dan microspatula.

b. Timbang sampel minyak goreng seberat 0,5 gram dan sampel gorengan yang sudah dihaluskan seberat 1 gram.

c. Masukkan sampel ke dalam gelas bekker $100 \mathrm{ml}$.

d. Panaskan hot plate dan letakkan gelas bekker yang telah berisi sampel di atas hot plate.

e. Panaskan sampel hingga mengering dan warnanya menghitam, kemudian teteskan asam sulfat sebanyak $3 \mathrm{ml}$ dan tunggu hingga mengeluarkan asap.

f. Setelah asap yang keluar cukup tebal, kecilkan hot plate dan teteskan asam nitrat sebanyak 2 $\mathrm{ml}$ pada pinggir gelas hingga larutan bening.

g. Teteskan asam sulfat dan asam nitrat secara bergantian sampai total masing-masing yang ditetekan yaitu $6 \mathrm{ml}$ asam sulfat dan $6 \mathrm{ml}$ asam nitrat.

h. Setelah seluruh sampel terlihat bening, turunkan dari hot plate dan diamkan hingga dingin.

i. Setelah dingin, lakukan pengenceran hingga larutan bervolume $25 \mathrm{ml}$.

j. Saring sampel menggunakan kertas saring dan dimasukkan ke dalam botol sampel.

k. Filtrat yang diperoleh digunakan untuk analisis logam timbal $(\mathrm{Pb})$.

2) Analisis Logam $\mathrm{Pb}$ dalam Sampel

Larutan sampel hasil destruksi diukur absorbansinya dengan 
Spektrofotometer Serapan Atom pada panjang gelombang $283 \mathrm{~nm}$.

3) Menghitung Konsentrasi Timbal (Pb) Rumus menghitung konsentrasi $\mathrm{Pb}=$

$$
\frac{C}{W} \times V
$$

Keterangan:

$\mathrm{C}=$ konsentrasi logam dari kurva kalibrasi dan dinyatakan dalam mikrogram per milliliter $(\mu \mathrm{g} / \mathrm{L})$

$\mathrm{V}=$ volume larutan akhir dan dinyatakan dalam milliliter (ml)

$\mathrm{W}=$ bobot contoh dan dinyatakan dalam gram $(\mathrm{g})$

Data yang dikumpulkan merupakan data primer yang terdiri dari hasil uji laboratorium konsentrasi logam berat timbal $(\mathrm{Pb})$ pada minyak goreng dan gorengan yang dianalisis di Laboratorium Fakultas MIPA Universitas Udayana dan Laboratorium Forensik Polresta Denpasar, serta kuisioner. Data yang dikumpulkan meliputi karakteristik data responden (lokasi pedagang, jenis kelamin, usia, dan pendidikan terakhir) dan karakteristik data umum penggorengan (jenis minyak, sumber minyak, waktu penggunaan minyak, frekuensi penggorengan, jenis wajan yang digunakan, alasan berjualan di lokasi saat ini, dan kondisi tempat berjualan. Data dianalisis secara deskriptif dengan menggunakan software SPSS 24.0 dan Microsoft Excel 2016.

\section{HASIL}

Pada penelitian ini, pengambilan sampel minyak goreng dan makanan berupa aneka jenis gorengan dilakukan di beberapa jalan yang berdekatan dengan traffic light dikarenakan jumlah paparan emisi kendaraan bermotor lebih banyak dihasilkan di daerah traffic light. Pengambilan sampel dilakukan di lima lokasi yaitu:

1. Sampel pertama (S1) terletak di Jl. Pratama.

2. Sampel kedua (S2) terletak di J1. By Pass Ngurah Rai.

3. Sampel ketiga (S3) terletak di Jl. By Pass Ngurah Rai.

4. Sampel keempat (S4) terletak di Jl. By Pass Ngurah Rai.

5. Sampel kelima (S5) terletak di Jl. Siligita. 
Tabel 1. Data Umum Lokasi Pedagang Di Persimpangan Kelurahan Benoa

\begin{tabular}{clcccc}
\hline Pedagang & $\begin{array}{c}\text { Lokasi } \\
\text { Persimpangan }\end{array}$ & $\begin{array}{c}\text { Lama Lampu } \\
\text { Merah } \\
\text { (detik) }\end{array}$ & $\begin{array}{c}\text { Panjang } \\
\text { Antrean } \\
\text { (m) }\end{array}$ & $\begin{array}{c}\text { Jarak Dari } \\
\text { Traffic Light } \\
\text { (m) }\end{array}$ & $\begin{array}{c}\text { Lama } \\
\text { Berdagang } \\
\text { (jam) }\end{array}$ \\
\hline S1 & $\begin{array}{l}\text { Simpang Pasar } \\
\text { Bualu }\end{array}$ & 80 & \pm 30 & \pm 90 & 7 \\
\hline S2 & $\begin{array}{l}\text { Simpang Pasar } \\
\text { Bualu }\end{array}$ & 80 & \pm 40 & \pm 70 & 4 \\
\hline S3 & $\begin{array}{l}\text { Simpang Arta } \\
\text { Sedana }\end{array}$ & 180 & \pm 70 & \pm 50 & 12 \\
\hline S4 & $\begin{array}{l}\text { Simpang Tol } \\
\text { Nusa Dua }\end{array}$ & 80 & \pm 50 & \pm 80 & 11 \\
\hline S5 & $\begin{array}{l}\text { Simpang Arta } \\
\text { Sedana }\end{array}$ & 180 & \pm 45 & \pm 60 & 8 \\
\hline
\end{tabular}

Tabel tersebut menunjukkan bahwa lampu merah menyala terlama berada pada Simpang Arta Sedana yaitu 180 detik, sedangkan paling sedikit ada pada dua persimpangan yaitu Simpang Pasar Bualu dan Simpang Tol Nusa Dua selama 80 detik. Antrean kendaraan bermotor terpanjang berada di Simpang Arta Sedana di Jl. By Pass Ngurah Rai yaitu sejauh \pm 70 meter, dan antrean terpendek berada di Simpang Pasar Bualu di Jl. Pratama yaitu sejauh \pm 30 meter. Jarak pedagang gorengan yang terjauh ada pada Simpang
Pasar Bualu di Jl. Pratama (S1) yaitu sejauh \pm 90 meter dari traffic light, sedangkan yang paling dekat adalah pedagang yang berjualan di Simpang Arta Sedana di Jl. By Pass Ngurah Rai (S3) yaitu sejauh \pm 50 meter dari traffic light. Pedagang dengan waktu berjualan yang paling lama berada di Simpang Arta Sedana di Jl. By Pass Ngurah Rai (S3) yaitu selama 12 jam, sedangkan yang paling sedikit berada di Simpang Pasar Bualu di Jl. By Pass Ngurah Rai (S2) yaitu selama 4 jam.

Tabel 2. Karakteristik Data Umum Responden Dan Data Umum Penggorengan

\begin{tabular}{|c|c|c|c|c|}
\hline No & Karakteristik & $F(N=5)$ & $(\%)$ & Mean \pm SD \\
\hline \multirow[t]{4}{*}{1} & Lokasi & & & \\
\hline & - Simpang Arta Sedana & 2 & 40,0 & \\
\hline & - $\quad$ Simpang Pasar Bualu & 2 & 40,0 & \\
\hline & - $\quad$ Simpang Tol Nusa Dua & 1 & 20,0 & \\
\hline \multirow[t]{3}{*}{2} & Jenis Kelamin & & & \\
\hline & - $\quad$ Laki-laki & 4 & 80,0 & \\
\hline & - $\quad$ Perempuan & 1 & 20,0 & \\
\hline
\end{tabular}




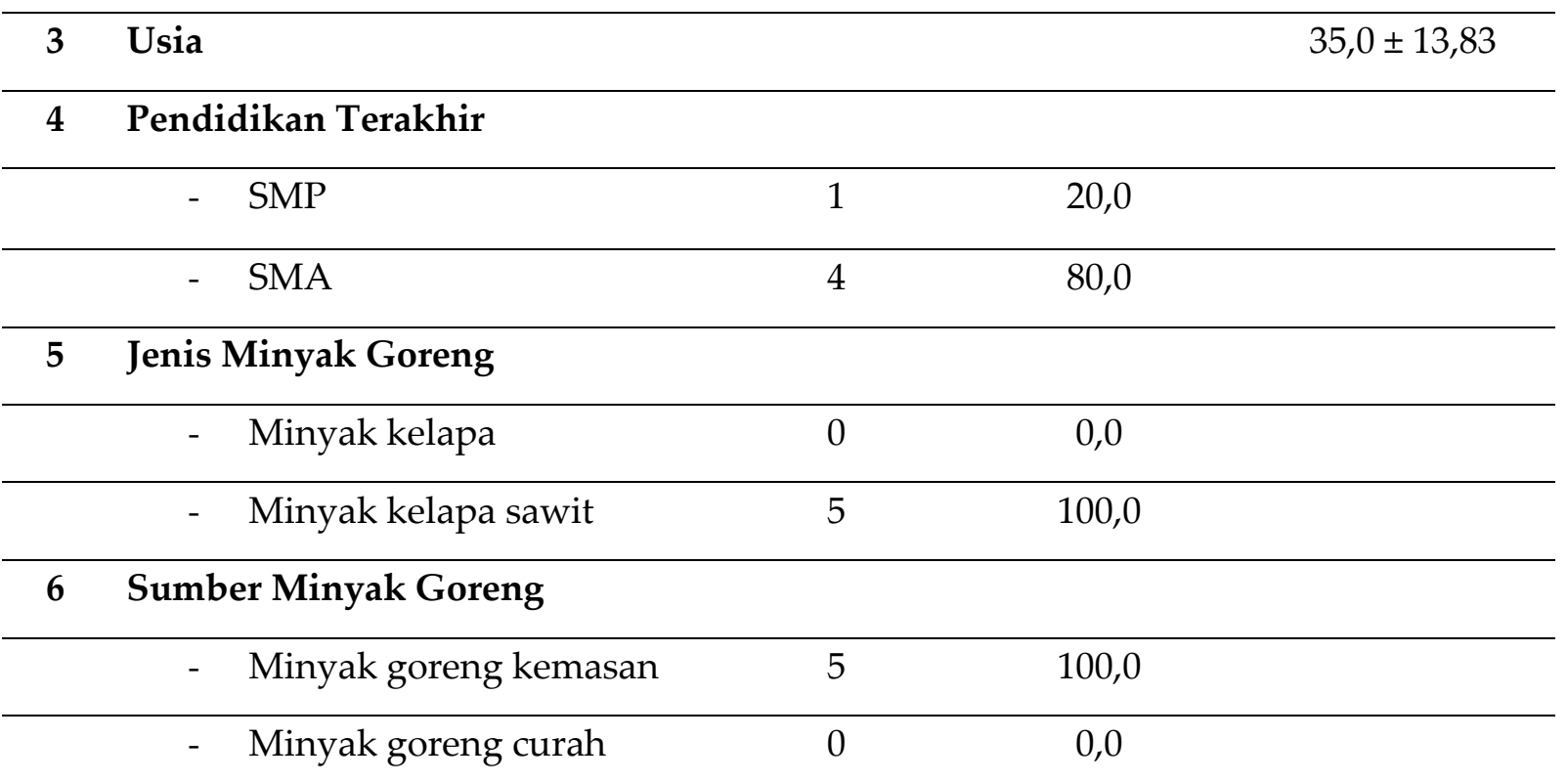

7 Waktu Penggunaan Minyak

\begin{tabular}{|c|c|c|c|c|}
\hline & - $\quad$ Mulai hari ini & 0 & 0,0 & \\
\hline & - $\quad$ Mulai kemarin & 5 & 100,0 & \\
\hline & - $\quad$ Mulai dari 2 hari yang lalu & 0 & 0,0 & \\
\hline 8 & $\begin{array}{l}\text { Frekuensi Penggorengan yang } \\
\text { Dilakukan }\end{array}$ & & & $5,40 \pm 2,88$ \\
\hline 9 & Jenis Wajan Penggorengan & & & \\
\hline & - Aluminium & 5 & 100,0 & \\
\hline & - $\quad$ Besi & 0 & 0,0 & \\
\hline 10 & $\begin{array}{l}\text { Alasan Berjualan di Lokasi Saat } \\
\text { Ini }\end{array}$ & & & \\
\hline & $\begin{array}{l}\text { - Agar lebih mudah } \\
\text { dijangkau }\end{array}$ & 4 & 80,0 & \\
\hline & - Tidak ada tempat lain & 1 & 20,0 & \\
\hline 11 & Kondisi Tempat Berjualan & & & \\
\hline & $\begin{array}{l}\text { - Kuali penggorengan di } \\
\text { tempat terbuka }\end{array}$ & 2 & 40,0 & \\
\hline & $\begin{array}{l}\text { - Kuali penggorengan } \\
\text { diberikan penghalang }\end{array}$ & 3 & 60,0 & \\
\hline
\end{tabular}

Pada tabel di atas telah dijelaskan bahwa terdapat 4 karakteristik responden yaitu lokasi, jenis kelamin, usia, dan pendidikan terakhir. Dilihat dari lokasinya, terdapat 3 lokasi pedagang gorengan yakni berada di Simpang Arta Sedana, Simpang Pasar Bualu, dan Simpang Tol Nusa Dua. Untuk menentukan jumlah pedagang di tiap persimpangan diperoleh dari observasi peneliti pada kegiatan survei 
pendahuluan. Sehingga responden yang didapat yaitu 2 pedagang dari Simpang Arta Sedana, 2 pedagang dari Simpang Pasar Bualu, dan 1 pedagang dari Simpang Tol Nusa Dua. Jika dilihat dari jenis kelamin responden, terdapat 4 orang pedagang dengan jenis kelamin laki-laki dan 1 orang pedagang dengan jenis kelamin perempuan.

Berdasarkan usia responden, diperoleh rerata usia responden yaitu 35,0 tahun dengan standar deviasi sebesar 13,83 . Nilai minimal dari usia responden adalah 19 tahun, sedangkan untuk nilai maksimal dari usia responden adalah 55 tahun. Dilihat dari pendidikan terakhir responden, sebanyak 1 orang responden merupakan lulusan SMP dan sebanyak 4 orang responden merupakan lulusan SMA.

Karakteristik data umum penggorengan, diantaranya jenis minyak goreng, sumber minyak goreng, waktu penggunaan minyak, frekuensi atau banyaknya penggorengan yang dilakukan, jenis wajan penggorengan, alasan berjualan di lokasi saat ini, dan terakhir kondisi tempat berjualan. Berdasarkan tabel karakteristik data umum penggorengan di atas, jenis minyak goreng yang dipakai menunjukkan bahwa seluruh responden menggunakan minyak kelapa sawit untuk menggoreng dan tidak ada responden yang menggunakan minyak kelapa. Selanjutnya berdasarkan sumber minyak yang digunakan juga menunjukkan bahwa seluruh responden menggunakan minyak goreng kemasan dan tidak ada responden yang menggunakan minyak goreng curah. Dilihat dari waktu penggunaan minyak goreng, seluruh responden menggunakan minyak goreng yang sudah digunakan kemarin dan tidak ada responden yang menggunakan minyak mulai hari ini ataupun mulai dari 2 hari yang lalu.

Berdasarkan frekuensi atau banyaknya penggorengan yang dilakukan, diperoleh rerata penggorengan yang dilakukan adalah 5,40 dengan standar deviasi sebesar 2,88. Nilai minimal dari frekuensi penggorengan yang dilakukan adalah sebanyak 3 kali, sedangkan untuk nilai maksimal dari frekuensi penggorengan yang dilakukan adalah sebanyak 10 kali. Berdasarkan jenis wajan penggorengan yang digunakan, seluruh responden menggunakan wajan dengan bahan aluminium dan tidak ada responden yang menggunakan wajan penggorengan yang terbuat dari besi. Dilihat dari alasan responden untuk berjualan di lokasi saat ini, ditunjukkan bahwa sebanyak 4 responden mengatakan alasan berjualan di lokasi saat ini karena agar lebih mudah dijangkau oleh calon pembeli, dan hanya terdapat 1 responden yang menjawab tidak ada tempat lain untuk berjualan. Berdasarkan kondisi tempat berjualan, sebanyak 2 responden terlihat bahwa kondisi kuali/wajan penggorengannya berada di tempat terbuka, dan sebanyak 3 responden terlihat bahwa kondisi kuali penggorengan diberikan penghalang. 
Tabel 3. Hasil Uji Logam Berat Pb Pada Minyak Goreng Dan Gorengan

\begin{tabular}{|c|c|c|c|c|}
\hline No & Jenis Sampel & $\begin{array}{c}\text { Kode } \\
\text { Sampel }\end{array}$ & $\begin{array}{l}\text { Konsentrasi } \mathbf{P b} \\
(\mathrm{ppm})\end{array}$ & Ket \\
\hline \multirow[t]{6}{*}{1} & Minyak Sebelum Penggorengan & S1a & 1,3253 & TMS \\
\hline & & S2a & 0,4365 & TMS \\
\hline & & S3a & 0,3888 & TMS \\
\hline & & $\mathrm{S} 4 \mathrm{a}$ & 0,5238 & TMS \\
\hline & & S5a & 0,3730 & TMS \\
\hline & Mean \pm SD & & $0,6094 \pm 0,4$ & \\
\hline \multirow[t]{6}{*}{2} & $\begin{array}{l}\text { Minyak Setelah Penggorengan Hari } \\
\text { Jumat }\end{array}$ & S1b & 0,1984 & TMS \\
\hline & & $\mathrm{S} 2 \mathrm{~b}$ & 0,2063 & TMS \\
\hline & & S3b & 0,2936 & TMS \\
\hline & & $\mathrm{S} 4 \mathrm{~b}$ & 0,3095 & TMS \\
\hline & & $\mathrm{S} 5 \mathrm{~b}$ & 0,2142 & TMS \\
\hline & Mean \pm SD & & $0,2444 \pm 0,52$ & \\
\hline 3 & $\begin{array}{l}\text { Minyak Setelah Penggorengan (Tanpa } \\
\text { Bahan Gorengan) }\end{array}$ & S1c & 0,3412 & TMS \\
\hline
\end{tabular}

\begin{tabular}{|c|c|c|c|c|}
\hline & & S2c & 0,4682 & TMS \\
\hline & & S3c & 0,3095 & TMS \\
\hline & & S4c & 0,3571 & TMS \\
\hline & & S5c & 0,4206 & TMS \\
\hline & Mean \pm SD & & $0,3793 \pm 0,64$ & \\
\hline \multirow[t]{6}{*}{4} & $\begin{array}{l}\text { Minyak Setelah Penggorengan Hari } \\
\text { Sabtu }\end{array}$ & S1b+ & 0,2143 & TMS \\
\hline & & $\mathrm{S} 2 \mathrm{~b}+$ & 0,2313 & TMS \\
\hline & & $\mathrm{S} 3 \mathrm{~b}+$ & 0,2340 & TMS \\
\hline & & $\mathrm{S} 4 \mathrm{~b}+$ & 0,2239 & TMS \\
\hline & & $\mathrm{S} 5 \mathrm{~b}+$ & 0,2235 & TMS \\
\hline & Mean \pm SD & & $0,2254 \pm 0,01$ & \\
\hline \multirow{2}{*}{\multicolumn{2}{|c|}{$5 \quad$ Gorengan }} & S1d & 0,2011 & MS \\
\hline & & S2d & 0,1408 & MS \\
\hline
\end{tabular}




\begin{tabular}{cccc}
\hline & S3d & 0,1496 & MS \\
\hline & S4d & 0,1360 & MS \\
\hline Mean \pm SD & & 0,1880 & MS \\
\hline
\end{tabular}

\section{Keterangan: - MS: Memenuhi Syarat}

\section{- TMS: Tidak Memenuhi Syarat}

Berdasarkan hasil uji logam berat timbal $(\mathrm{Pb})$ dengan metode Spektrofotometri Serapan Atom (SSA), ditunjukkan bahwa hampir seluruh sampel memiliki kandungan logam $\mathrm{Pb}$ di dalamnya dan sudah melebihi batas maksimum logam $\mathrm{Pb}$. Adapun rerata dari konsentrasi logam berat $\mathrm{Pb}$ pada minyak sebelum penggorengan adalah $0,60 \mathrm{ppm}$ dengan standar deviasi sebesar 0,4. Rerata dari konsentrasi logam $\mathrm{Pb}$ pada minyak setelah penggorengan yang diambil pada hari Jumat adalah 0,24 ppm dengan standar deviasi sebesar 0,52. Rerata dari konsentrasi logam $\mathrm{Pb}$ pada minyak setelah penggorengan (tanpa bahan gorengan) adalah 0,37 ppm dengan standar deviasi sebesar 0,64. Rerata dari konsentrasi logam $\mathrm{Pb}$ pada minyak setelah penggorengan yang diambil pada hari Sabtu adalah 0,22 ppm dengan standar deviasi sebesar 0,01.
Nilai rerata dari seluruh sampel minyak goreng ini tidak memenuhi syarat sesuai standar yang ditetapkan oleh Badan Standarisasi Nasional Indonesia yang dipublikasikan dalam SNI 7387:2009 tentang Batas Maksimum Cemaran Logam Berat dalam Pangan tahun 2009 dengan batas maksimum logam $\mathrm{Pb}$ pada minyak yaitu $0,1 \mathrm{mg} / \mathrm{kg}$ (ppm). Sedangkan rerata dari konsentrasi logam $\mathrm{Pb}$ pada sampel gorengan adalah 0,16 ppm dengan standar deviasi 0,03. Nilai rerata pada sampel gorengan menunjukkan bahwa seluruh sampel memenuhi syarat sesuai standar yang ditetapkan dalam Peraturan BPOM RI Nomor HK.00.06.1.52.4011 tentang Penetapan Batas Maksimum Cemaran Mikroba dan Kimia dalam Makanan dimana batas maksmimum logam $\mathrm{Pb}$ pada pangan olahan lainnya yaitu $0,25 \mathrm{mg} / \mathrm{kg}$ (ppm).

Tabel 4. Persentase Perbandingan Konsentrasi Pb Pada Minyak Sebelum Dan Sesudah Penggorengan Hari Jumat

\begin{tabular}{ccccc}
\hline No & Pedagang & Sebelum Penggorengan & Sesudah Penggorengan & $\%$ \\
\hline 1 & S1 & 1,3253 & 0,1984 & $-85 \%$ \\
\hline 2 & S2 & 0,4365 & 0,2063 & $-53 \%$ \\
\hline 3 & S3 & 0,3888 & 0,2936 & $-24 \%$ \\
\hline 4 & S4 & 0,5238 & 0,3095 & $-41 \%$ \\
\hline 5 & S5 & 0,3730 & 0,2142 & $-43 \%$
\end{tabular}


Berdasarkan tabel di atas, dapat terlihat bahwa seluruh sampel minyak sesudah penggorengan yang diambil pada hari Jumat mengalami penurunan konsentrasi logam $\mathrm{Pb}$ dibandingkan dengan minyak sebelum penggorengan. Pada sampel minyak yang berasal dari pedagang S1 mengalami penurunan konsentrasi $\mathrm{Pb}$ sebanyak $85 \%$, minyak yang berasal dari pedagang S2 mengalami penurunan konsentrasi $\mathrm{Pb}$ sebanyak 53\%, minyak yang berasal dari pedagang S3 mengalami penurunan konsentrasi $\mathrm{Pb}$ sebanyak $24 \%$, minyak yang berasal dari pedagang S4 mengalami penurunan konsentrasi $\mathrm{Pb}$ sebanyak 41\%, dan terakhir minyak yang berasal dari pedagang S5 mengalami penurunan konsentrasi $\mathrm{Pb}$ sebanyak 43\%. Adapun sampel minyak goreng yang mengalami penurunan paling tinggi adalah minyak yang berasal dari pedagang S1 yaitu sebanyak $85 \%$, sedangkan sampel minyak yang mengalami penurunan konsentrasi $\mathrm{Pb}$ paling rendah berasal dari pedagang S3 yaitu sebanyak $24 \%$.

Tabel 5. Persentase Perbandingan Konsentrasi Pb Pada Minyak Sebelum dan Sesudah Penggorengan (Tanpa Bahan Penggorengan)

\begin{tabular}{ccccc}
\hline No & Pedagang & Sebelum Penggorengan & $\begin{array}{c}\text { Sesudah Penggorengan } \\
\text { (Tanpa Bahan Gorengan) }\end{array}$ & $\%$ \\
\hline 1 & S1 & 1,3253 & 0,3412 & $-74 \%$ \\
\hline 2 & S2 & 0,4365 & 0,4682 & $7 \%$ \\
\hline 3 & S3 & 0,3888 & 0,3095 & $-20 \%$ \\
\hline 4 & S4 & 0,5238 & 0,3571 & $-32 \%$ \\
\hline 5 & S5 & 0,3730 & 0,4206 & $13 \%$ \\
\hline
\end{tabular}

Berdasarkan tabel di atas, dapat terlihat bahwa beberapa sampel minyak sesudah penggorengan (tanpa bahan gorengan) yang diambil pada hari Jumat mengalami penurunan konsentrasi logam $\mathrm{Pb}$ dan beberapa sampel lainnya mengalami peningkatan konsentrasi $\mathrm{Pb}$ setelah dibandingkan dengan minyak sebelum penggorengan. Beberapa sampel yang mengalami penurunan konsentrasi $\mathrm{Pb}$, antara lain sampel minyak yang berasal dari pedagang S1 yaitu sebanyak $74 \%$, minyak yang berasal dari pedagang S3 yaitu sebanyak 20\%, dan minyak yang berasal dari pedagang S4 yaitu sebanyak $32 \%$. Adapun sampel minyak goreng yang mengalami peningkatan konsentrasi $\mathrm{Pb}$, antara lain minyak yang berasal dari pedagang S2 yaitu sebanyak $7 \%$, dan minyak yang berasal dari pedagang S5 yaitu sebanyak 13\%. Berdasarkan persentasenya, sampel minyak dengan persentase paling tinggi adalah minyak yang berasal dari pedagang S5 yaitu mengalami peningkatan sebanyak 13\%, sedangkan sampel minyak dengan 
persentase yang paling rendah adalah minyak yang berasal dari pedagang S1 yaitu mengalami penurunan sebanyak $74 \%$.

\section{DISKUSI}

\section{Data Umum Lokasi Pedagang Gorengan di Kelurahan Benoa}

Makanan yang dijual di pinggir jalan adalah salah satu contoh makanan yang berisiko tercemar logam berat timbal $(\mathrm{Pb})$. Dari beberapa kalangan yang sangat memperhatikan gizi dari tiap makanan yang dikonsumsi, melihat bahwa makanan yang dijual di pinggir jalan khususnya gorengan merupakan makanan yang berbahaya bagi kesehatan. Salah satu alasannya adalah faktor kondisi sekitar pedagang yang menyebabkan gorengan menjadi tidak sehat untuk dikonsumsi (Bella and Erlani, 2020).

Dilihat berdasarkan keadaan umum lokasi persimpangan dimana sampel penelitian diambil menunjukkan bahwa lampu merah menyala terlama berada pada Simpang Arta Sedana yaitu 180 detik, dan antrean kendaraan bermotor terpanjang berada di Simpang Arta Sedana di Jl. By Pass Ngurah Rai (S3) yaitu sejauh \pm 70 meter. Lama lampu merah menyala ini terhitung dimulai dari lampu merah mulai menyala sampai lampu hijau mulai menyala di jalan tersebut. Sedangkan antrean kendaraan terhitung dimulai dari kendaraan paling depan yang paling dekat dengan traffic light sampai kendaraan yang paling terakhir di jalan tersebut. Jarak pedagang gorengan yang paling dekat adalah pedagang yang berjualan di Simpang Arta Sedana di Jl. By Pass Ngurah Rai (S3) yaitu sejauh \pm 50 meter dari traffic light. Pedagang dengan waktu berjualan yang paling lama berada di Simpang Arta Sedana di Jl. By Pass Ngurah Rai (S3) yaitu selama 12 jam. Waktu berjualan pedagang terhitung dimulai dari pedagang buka hingga tutup yaitu mulai dari pukul 09.00 21.00 WITA. Jika dilihat dari kondisi tersebut, pedagang yang berjualan di Simpang Arta Sedana di Jl. By Pass Ngurah Rai (S3) merupakan pedagang yang paling berisiko dengan faktor risiko polutan timbal $(\mathrm{Pb})$ yang terbawa dari asap kendaraan bermotor dapat mencemari sekitarnya. Semakin lama lampu merah, panjang antrean kendaraan, dan lama berdagang, maka semakin panjang pula waktu paparan timbal $(\mathrm{Pb})$ terhadap minyak goreng. Semakin dekat jarak pedagang dengan traffic light, semakin mudah dan tinggi pula risiko terpapar logam berat timbal $(\mathrm{Pb})$. Jumlah kendaraan per menit yang berada di traffic light juga mempengaruhi emisi dan paparan $\mathrm{Pb}$ terhadap minyak goreng yang digunakan pedagang.

\section{Karakteristik Data Umum Responden dan Data Umum Penggorengan}

Dilihat dari karakteristik responden, terdapat beberapa karakteristik, diantaranya lokasi pedagang, jenis kelamin, usia, dan pendidikan terakhir. Dilihat dari lokasinya, terdapat 2 pedagang dari Simpang Arta Sedana, 2 pedagang dari Simpang Pasar Bualu, dan 1 pedagang dari Simpang Tol Nusa Dua. Berdasarkan lokasi pedagang yang berada di kawasan persimpangan ini, pemakaian minyak untuk menggoreng yang berada di kawasan traffic light dapat meningkatkan kadar timbal $(\mathrm{Pb})$ hingga melebihi batas 
maksimum. Ditemukan sesuai dengan prinsip hygiene dan sanitasi makanan dalam menghindari paparan asap kendaraan bermotor pada makanan (Hasibuan, Hasan and Naria, 2012).

Jika dilihat dari jenis kelamin responden, terdapat 4 orang pedagang dengan jenis kelamin laki-laki dan 1 orang pedagang dengan jenis kelamin perempuan. Dalam hal ini pedagang lakilaki lebih banyak daripada pedagang perempuan dikarenakan jam buka pedagang gorengan yang biasanya buka dari sore hari hingga larut malam, sehingga laki-laki lebih dominan dibandingkan dengan perempuan karena alasan keamanan. Berdasarkan usia pedagang, diperoleh rentang usia responden yaitu usia 19 - 55 tahun dengan rerata 35,0 tahun. Sedangkan dilihat dari pendidikan terakhir responden, sebanyak 4 orang responden merupakan lulusan SMA. Berdasarkan usia dan pendidikan terakhir pedagang, seharusnya pedagang lebih mengetahui tentang batas aman penggunaan minyak goreng serta memperhatikan hygiene dan sanitasi di lingkungan sekitar pedagang gorengan, ditambah lagi dengan lokasi pedagang yang berdekatan dengan sumber emisi kendaraan bermotor yang lumayan tinggi.

Dilihat dari karakteristik data umum penggorengan, terdapat beberapa karakteristik diantaranya jenis minyak goreng, sumber minyak goreng, waktu penggunaan minyak, frekuensi atau banyaknya penggorengan yang dilakukan, jenis wajan penggorengan, alasan berjualan di lokasi saat ini, dan terakhir kondisi tempat berjualan. Berdasarkan karakteristik tersebut, jenis minyak goreng yang dipakai menunjukkan bahwa seluruh responden menggunakan minyak kelapa sawit dan sumber minyak yang digunakan adalah minyak goreng kemasan. Dilihat dari waktu penggunaan minyak goreng, seluruh responden menggunakan minyak goreng yang sudah digunakan kemarin. Pedagang mengaku bahwa mereka menggunakan campuran minyak goreng bekas penggorengan sehari sebelumnya dengan minyak goreng yang baru untuk penggorengan pertama kali setiap hari, dimana minyak yang digunakan sebelumnya sudah terlebih dahulu terpapar oleh timbal $(\mathrm{Pb})$. Dalam hal ini, pedagang beranggapan bahwa minyak yang digunakan kualitasnya masih lumayan baik, sehingga untuk pemakaian pertama setiap harinya dapat digunakan kembali lalu dicampurkan dengan minyak goreng yang baru dan dapat menghemat penggunaan minyak goreng.

Berdasarkan frekuensi atau banyaknya penggorengan yang dilakukan, diperoleh rerata penggorengan yang dilakukan adalah 5,40 dengan standar deviasi sebesar 2,88. Nilai minimal dari frekuensi penggorengan yang dilakukan adalah sebanyak 3 kali, sedangkan untuk nilai maksimalnya sebanyak 10 kali. Beberapa pedagang melakukan aktivitas penggorengan lebih dari 3 kali untuk setiap pergantian minyak goreng karena pedagang menganggap bahwa warna minyak masih tampak bening, kotoran sisa penggorengan belum begitu banyak, sehingga kualitasnya dianggap masih baik dan layak digunakan hingga perubahan warna tampak lebih gelap.

Berdasarkan jenis wajan penggorengan yang digunakan, seluruh 
responden menggunakan wajan dengan bahan aluminium. Menurut Yuliono (2006), bahan aluminium banyak digunakan karena memiliki sifat tahan terhadap korosi, tidak beracun, dan penghantar panas yang baik. Maka dari itu, aluminium sering digunakan sebagai alat rumah tangga seperti wajan penggorengan dan panci karena reaksi kimia antara bahan makanan dan aluminium tidak menghasilkan zat beracun yang berbahaya bagi manusia (Yuliono, 2006).

Dilihat dari alasan responden untuk berjualan di lokasi saat ini, ditunjukkan bahwa sebanyak 4 responden mengatakan alasan berjualan di lokasi saat ini karena agar lebih mudah dijangkau oleh calon pembeli, dan hanya terdapat 1 responden yang menjawab tidak ada tempat lain untuk berjualan. Hal ini karena pedagang merasa jika pedagang menjajakan dagangannya tepat di pinggir jalan raya yang ramai akan kendaraan bermotor yang berlalu lalang sehingga sangat strategis dan tentunya menjadi kondisi yang bagus untuk mendatangkan keuntungan bagi mereka.

Berdasarkan kondisi tempat berjualan, sebanyak 2 responden terlihat bahwa kondisi kuali atau wajan penggorengannya berada di tempat terbuka, sedangkan sebanyak 3 responden terlihat bahwa kondisi kuali penggorengan diberikan penghalang. Para pedagang gorengan tampak berusaha menjaga kondisi penggorengan dan sekitar dagangan dalam keadaan bersih, namun masih terdapat beberapa pedagang yang tidak membuat penghalang di sekitar penggorengan untuk mengurangi paparan asap kendaraan bermotor dan debu.
Kegunaan penghalang pada penggorengan sangat berguna untuk mengurangi paparan timbal $(\mathrm{Pb})$ dari udara yang mungkin dapat mencemari minyak goreng.

\section{Konsentrasi Logam Berat Timbal (Pb) pada Minyak Sebelum, Sesudah Penggorengan, dan Gorengan}

Pengukuran konsentrasi logam berat timbal $(\mathrm{Pb})$ pada sampel minyak dan gorengan yang diambil pada 5 pedagang gorengan di Kelurahan Benoa diperoleh dalam satuan $\mathrm{mg} / \mathrm{kg}$ (ppm). Menurut Badan Standarisasi Nasional Indonesia yang dipublikasikan dalam SNI 7387:2009 tentang Batas Maksimum Cemaran Logam Berat dalam Pangan tahun 2009 dengan batas maksimum logam $\mathrm{Pb}$ pada minyak yaitu $0,1 \quad \mathrm{mg} / \mathrm{kg} \quad$ (ppm) (Badan Standardisasi Nasional, 2009). Jika dibandingkan dengan nilai standar peraturan di atas, konsentrasi $\mathrm{Pb}$ pada minyak sebelum dan sesudah penggorengan dari pedagang gorengan di Kelurahan Benoa didapatkan seluruh sampel sudah melebihi nilai standar yang ditetapkan. Dalam penelitian yang dilakukan Yani (2011) menyimpulkan bahwa faktor-faktor yang dapat mempengaruhi terjadinya peningkatan kandungan $\mathrm{Pb}$ pada saat penggorengan, yaitu sumber minyak dan penggorengan berulang. Faktor tersebut secara positif menunjukkan pengaruh yang signifikan terhadap tingginya kadar timbal dalam minyak goreng (Yani, 2011). Tingginya kadar $\mathrm{Pb}$ dapat meningkatkan risiko penyakit bagi orang yang mengonsumsi gorengan tersebut karena minyak yang masih terdapat pada daerah outer zone 
gorengan yang ikut termakan (Hasibuan, Hasan and Naria, 2012). Untuk menghindari hal tersebut, satu-satunya cara adalah dengan tidak menggunakan minyak goreng yang sudah digunakan sehari atau lebih dari sehari sebelum penggorengan.

Sedangkan batas maksimum

konsentrasi $\mathrm{Pb}$ pada gorengan menurut Peraturan BPOM RI Nomor HK.00.06.1.52.4011 tentang Penetapan Batas Maksimum Cemaran Mikroba dan Kimia dalam Makanan dimana batas maksimum logam $\mathrm{Pb}$ pada pangan olahan lainnya yaitu 0,25 mg/kg (ppm) (BPOM RI, 2009). Jika dibandingkan dengan nilai standar peraturan di atas, konsentrasi $\mathrm{Pb}$ pada gorengan yang dijual oleh pedagang gorengan di Kelurahan Benoa didapatkan seluruh sampel belum melebihi nilai standar yang ditetapkan. Walaupun belum melebihi nilai standar, kandungan $\mathrm{Pb}$ pada gorengan ini hampir setara dengan kandungan $\mathrm{Pb}$ pada minyak goreng. Manusia dapat terkontaminasi logam $\mathrm{Pb}$ melalui makanan sebanyak 65\%, melalui air sebanyak 20\%, dan melalui udara sebanyak 1\% (Bella and Erlani, 2020). Yang artinya jika gorengan tersebut sering dikonsumsi, logam timbal akan terakumulasi dalam tubuh dan mengakibatkan kerugian berupa gangguan dan kerusakan pada saraf, hati, ginjal, tulang, dan otak.

Persentase Perbandingan Konsentrasi Logam Berat $\mathrm{Pb}$ pada Minyak

a. Perbandingan Konsentrasi Timbal Pada Minyak Sebelum dan Sesudah Penggorengan yang Diambil Pada hari Jumat
Berdasarkan hasil uji logam berat timbal $(\mathrm{Pb})$ dengan metode Spektrofotometri Serapan Atom (SSA), ditunjukkan bahwa rerata dari konsentrasi logam berat $\mathrm{Pb}$ pada minyak sebelum penggorengan adalah 0,60 ppm dengan standar deviasi sebesar 0,4 yang artinya konsentrasi $\mathrm{Pb}$ tersebut sudah melebihi ambang batas. Hal ini dikarenakan pemakaian minyak yang sudah digunakan dari sehari sebelumnya dan dengan penambahan minyak baru dari minyak kemasan untuk melakukan penggorengan. Sehingga walaupun minyak sudah ditambahkan dengan minyak baru, minyak tersebut sudah mengandung timbal $(\mathrm{Pb})$ cukup tinggi sejak awal penggorengan dilakukan. Kandungan $\mathrm{Pb}$ di dalam tubuh manusia berkisar antara 100-400 mg. Sumber masuknya timbal ke dalam tubuh dapat berasal dari makanan, terutama bagi mereka yang tidak melakukan kontak dengan timbal diperkirakan rata-rata $300 \mu \mathrm{g}$ per hari dengan kisaran 100-500 $\mu$ g per hari (Bella and Erlani, 2020). Jika penggunaan minyak ini terus terjadi, timbal dapat masuk ke dalam tubuh konsumen secara bertahap sehingga dapat membahayakan kesehatan konsumen.

Rerata dari konsentrasi logam $\mathrm{Pb}$ pada minyak setelah penggorengan yang diambil pada hari Jumat adalah 0,24 ppm dengan standar deviasi sebesar 0,52. Jika dibandingkan dengan minyak sebelum penggorengan dapat terlihat bahwa seluruh sampel minyak sesudah penggorengan yang diambil pada hari Jumat mengalami penurunan. Hal ini dapat terjadi karena minyak tersebut sudah melalui proses penggorengan 
dimana kandungan $\mathrm{Pb}$ pada minyak kemungkinan teradsorpsi pada gorengan. Bukti tersebut dapat dilihat dari rerata konsentrasi logam $\mathrm{Pb}$ pada sampel gorengan adalah 0,16 ppm dengan standar deviasi 0,03.

Tepung terigu memiliki gluten yang tidak dimiliki oleh jenis tepung lainnya. Gluten mampu memerangkap gas ketika proses penggorengan berlangsung menyebabkan struktur berongga dan mampu meningkatkan kerenyahan. Struktur yang dibentuk oleh gluten inilah yang kemudian merupakan jalan bagi air dan minyak (Allisan, 2019). Kapasitas penyerapan minyak pada tepung juga dipengaruhi oleh kadar protein atau lemaknya, dimana tepung terigu ada yang berprotein rendah dan berprotein tinggi (Aini, Wijonarko and Sustriawan, 2016). Kandungan timbal pada gorengan dapat disebabkan oleh beberapa faktor, yaitu pencemaran udara berupa gas emisi buangan kendaraan bermotor, peralatan dapur, kertas kemasan dan non kemasan, bahan yang digunakan, serta minyak goreng yang dipakai (Bella and Erlani, 2020).

b. Perbandingan Konsentrasi Timbal

Pada Minyak Sebelum dan Sesudah

Penggorengan (Tanpa Bahan

Gorengan)

Rerata dari konsentrasi logam $\mathrm{Pb}$ pada minyak sesudah penggorengan (tanpa bahan gorengan) adalah 0,37 ppm dengan standar deviasi sebesar 0,64. Jika dibandingkan dengan minyak sebelum penggorengan dapat terlihat bahwa rerata sampel minyak sesudah penggorengan (tanpa bahan gorengan) mengalami penurunan. Namun, terdapat beberapa sampel yang mengalami peningkatan konsentrasi $\mathrm{Pb}$ dikarenakan volume kendaraan pada saat melakukan penggorengan sedang meningkat, seperti sepeda motor, mobil, dan kendaraan lain yang berbahan bakar bensin. Seperti yang telah disebutkan sebelumnya, lokasi pedagang gorengan yang berada di dekat persimpangan jalan raya merupakan salah satu faktor risiko terpapar timbal. Hal ini dikarenakan banyaknya volume kendaraan bermotor mengeluarkan emisi asapnya. Darmono (1995) mengatakan, asap kendaraan bermotor menyumbang polusi udara sebesar 60-70\%. Sehingga pada prinsipnya, pedagang gorengan sebenarnya berada pada kawasan risiko terpapar asap yang mengandung $\mathrm{Pb}$ setiap harinya.

c. Perbandingan Konsentrasi Timbal Pada Minyak Sesudah Penggorengan yang Diambil Pada Hari Jumat dan Sabtu

Rerata dari konsentrasi logam $\mathrm{Pb}$ pada minyak setelah penggorengan yang diambil pada hari Sabtu adalah 0,22 ppm dengan standar deviasi sebesar 0,01. Jika dibandingkan dengan minyak sesudah penggorengan yang diambil pada hari Jumat dapat terlihat bahwa rerata sampel minyak sesudah penggorengan yang diambil pada hari Sabtu mengalami penurunan. Namun, terdapat beberapa sampel yang mengalami peningkatan konsentrasi $\mathrm{Pb}$ dikarenakan hari Sabtu merupakan hari libur dimana volume kendaraan di 2 persimpangan yaitu Simpang Pasar Bualu dan Simpang Tol Nusa Dua pada saat itu sedang meningkat. Menurut Bella dan Erlani (2020), tingginya jumlah kendaraan yang lalu lalang 
mengakibatkan terjadinya antrean kendaraan sedangkan kontaminasi $\mathrm{Pb}$ pada saat macet dibandingkan pada saat kendaraan tersebut jalan yaitu komposisi persen dari total partikel $\mathrm{Pb}$ di dalam asap kendaraan bermotor sesaat setelah macet lebih tinggi sehingga menimbulkan polusi udara dengan konsentrasi $\mathrm{Pb}$ yang lebih tinggi pula (Bella and Erlani, 2020). Polusi $\mathrm{Pb}$ di kawasan jalan raya sangat tergantung pada beberapa faktor, yaitu kecepatan lalu lintas, jarak pedagang terhadap jalan raya, arah dan kecepatan angin, cara mengendarai kendaraan, dan kecepatan kendaraan (Ulandari, Laenggeng and Rosnawati, 2018).

d. Perbandingan Konsentrasi Timbal Pada Minyak Sesudah Penggorengan dan Minyak Sesudah Penggorengan (Tanpa Bahan Gorengan) yang Diambil Pada Hari Jumat

Rerata dari konsentrasi logam $\mathrm{Pb}$ pada minyak sesudah penggorengan (tanpa bahan gorengan) jika dibandingkan dengan rerata minyak sesudah penggorengan yang diambil pada hari Jumat dapat terlihat bahwa rerata sampel minyak sesudah penggorengan (tanpa bahan gorengan) mengalami peningkatan. Hal ini membuktikan bahwa kandungan timbal $(\mathrm{Pb})$ yang terdapat pada minyak berasal dari asap kendaraan bermotor karena konsentrasi minyak sesudah penggorengan lebih kecil setelah dilakukan penggorengan dimana minyak juga terserap ke dalam gorengan. Sedangkan minyak sesudah penggorengan (tanpa bahan gorengan) tidak melakukan penggorengan apapun, yang artinya $\mathrm{Pb}$ berasal dari emisi asap kendaran bermotor.
Selain itu, peningkatan konsentrasi $\mathrm{Pb}$ ini terjadi bukan karena penguapan minyak pada saat menggoreng dan terjadi pengurangan volume minyak dan meningkatkan kadar $\mathrm{Pb}$. Hal ini dibuktikan dengan suhu penggorengan atau titik didih minyak goreng yaitu sebesar 170$185^{\circ} \mathrm{C}$, sedangkan titik uap pada minyak sebesar $190^{\circ} \mathrm{C}$. Artinya pada saat penggorengan terjadi, minyak goreng tidak menguap sehingga kadar $\mathrm{Pb}$ yang meningkat berhubungan dengan masuknya timbal $(\mathrm{Pb})$ ke dalam minyak goreng yang dapat berasal dari asap kendaraan bermotor yang bertebaran.

\section{SIMPULAN}

Berdasarkan hasil penelitian yang telah dilakukan menunjukkan lamanya waktu lampu merah menyala berkisar antara 80 - 180 detik, antrean kendaraan bermotor berkisar antara 30 - 70 meter, jarak pedagang gorengan dari traffic light berkisar antara 50 - 90 meter, dan lamanya waktu berjualan oleh pedagang berkisar antara 4 - 12 jam.

Seluruh responden menggunakan minyak kelapa sawit, sumber minyak yang digunakan adalah minyak goreng kemasan, menggunakan minyak goreng yang sudah digunakan dari kemarin, dan jenis wajan yang digunakan adalah wajan aluminium. Frekuensi penggorengan yang dilakukan berkisar antara 3 - 10 kali, alasan responden untuk berjualan di lokasi saat ini ditunjukkan bahwa lebih banyak responden mengatakan agar lebih mudah dijangkau oleh calon pembeli, sedangkan untuk kondisi tempat berjualan, lebih banyak responden terlihat bahwa kondisi kuali penggorengan diberikan penghalang. 
Konsentrasi logam berat timbal $(\mathrm{Pb})$ yang terdapat pada seluruh jenis minyak telah melebihi batas maksimum logam $\mathrm{Pb}$ pada minyak yang diatur dalam SNI 7387:2009 yaitu 0,1 ppm. Sedangkan konsentrasi $\mathrm{Pb}$ yang terdapat pada gorengan tidak melebihi batas maksimum $\mathrm{Pb}$ pada olahan pangan lainnya yang diatur dalam Peraturan BPOM RI Nomor HK.00.06.1.52.4011 yaitu 0,25 ppm.

Perbandingan persentase pada seluruh sampel minyak sesudah penggorengan yang diambil pada hari Jumat mengalami penurunan konsentrasi $\mathrm{Pb}$ dibandingkan dengan minyak sesudah penggorengan. Terdapat 2 sampel minyak sesudah penggorengan (tanpa bahan gorengan) yang mengalami peningkatan konsentrasi $\mathrm{Pb}$ dan 3 sampel yang mengalami penurunan dibandingkan dengan minyak sebelum penggorengan.

\section{SARAN}

Kepada pedagang gorengan sebaiknya lebih memperhatikan kondisi lingkungan pada dagangannya, seperti jarak tempat berdagang yang harus diperhatikan, pemakaian minyak goreng yang tidak berulang, dan memberikan penghalang atau penutup pada wajan penggorengan agar dapat mengurangi paparan asap kendaraan bermotor yang mengandung logam timbal $(\mathrm{Pb})$.

Kepada para konsumen hendaknya agar lebih berhati-hati dan selektif membeli makanan jajanan dan disarankan untuk mengurangi asupan gorengan mengingat cemaran timbal dalam minyak goreng melebihi ambang batas dan gorengan hampir melebihi ambang batas.
Kepada Dinas Kesehatan Kabupaten Badung atau BPOM agar memberikan penyuluhan kepada pedagang tentang bahaya logam berat terutama timbal pada makanan.

\section{UCAPAN TERIMA KASIH}

Terimakasih kepada responden penelitian dan staf laboratorium, terutama kepada dosen pembimbing dan keluarga yang telah memberikan kontribusi dalam pelaksanaan penelitian ini.

\section{DAFTAR PUSTAKA}

Aini, N., Wijonarko, G. and Sustriawan, B. (2016) 'Sifat Fisik, Kimia, dan Fungsional Tepung Jagung yang Diproses Melalui Fermentasi', Jurnal Agritech, 36(2), pp. 160-169. doi: 10.22146/agritech. 12860 .

Allisan, S. (2019) Pengaruh Perbandingan Tepung Terigu, Tepung Beras Pera, Tepung Maizena dan Konsentrasi Bahan Perenyah Terhadap Karakteristik Tepung Bumbu Ayam Crispy. Universitas Pasundan.

Alsuhendra and Ridawati (2013) Bahan Toksik Dalam Makanan. Bandung: PT. Remaja Rosdakarya.

Ariani, D., Yanti, S. and Saputri, D. S. (2017) 'Studi Kualitatif Dan Kuantitatif Minyak Goreng yang Digunakan Oleh Penjual Gorengan di Kota Sumbawa', Jurnal TAMBORA, 2(3), pp. 1-8. doi: 10.36761/jt.v2i3.173.

Badan Pusat Statistik Indonesia (2020) Jumlah Kendaraan Bermotor Menurut Provinsi dan Jenis Kendaraan (Unit) 2019. Available at: https://www.bps.go.id/indikator/ind 
ikator/view_data_pub/0000/api_pub /150/da_10/1 (Accessed: 5 January 2021).

Badan Pusat Statistik Kabupaten Badung (2020) Kecamatan Kuta Selatan Dalam Angka 2020. Edited by BPS Kabupaten Badung. Badung: BPS Kabupaten Badung.

Badan Pusat Statistik Provinsi Bali (2020) Banyaknya Kendaraan Bermotor Menurut Kabupaten/Kota di Bali 20102019. Available at: https://bali.bps.go.id/dynamictable/2 018/02/02/217/banyaknya-

kendaraan-bermotor-menurut-

kabupaten-kota-di-bali-2010-

2016.html (Accessed: 5 January 2021).

Badan Standardisasi Nasional (2009) ‘Batas

Maksimum Cemaran Logam Berat dalam Pangan', SNI 7387:2009.

Bella, A. N. F. K. and Erlani (2020) 'Analisis Kandungan Logam Berat Timbal (Pb) Pada Jajanan Gorengan di Kota Makassar', Jurnal Sulolipu: Media Komunikasi Sivitas Akademika dan Masyarakat, 20(1), pp. 135-143. doi: 10.32382/sulolipu.v20i1.1441.

BPOM RI (2009) Penetapan Batas Maksimum Cemaran Mikroba dan Kimia dalam Makanan. Indonesia.

Darmono (1995) Logam Berat Dalam Sistem Biologi. Jakarta: UI Press.

Hasibuan, R., Hasan, W. and Naria, E. (2012) 'Analisa Kandungan Timbal $(\mathrm{Pb})$ Pada Minyak Sebelum dan Sesudah Penggorengan yang Digunakan Pedagang Gorengan
Sekitar Kawasan Traffic Light Kota Medan Tahun 2012', Journal of Chemical Information and Modeling.

Menteri Kesehatan Republik Indonesia (2002) Standar Pemeriksaan Kadar Timah Hitam Pada Spesimen Biomarker Manusia. Indonesia.

Perdana, A. P., Sy, E. and Yerizel, E. (2017) 'Analisis Kandungan Timbal Pada Gorengan yang Dijual Sekitar Pasar Ulakan Tapakis Padang Pariaman Secara Spektrofotometri Serapan Atom', Artikel Penelitian, 6(3), pp. 490-494. doi: 10.25077/jka.v6i3.727.

Sudarma, N. (2020) 'Hubungan Kadar Timbal $(\mathrm{Pb})$ Dalam Darah Dengan Pekerja di Terminal Ubung Denpasar 2019', Sintesa Prosiding 2020, pp. 265 274.

Ulandari, S., Laenggeng, A. H. and Rosnawati (2018) 'Analisis Kadar Timbal $(\mathrm{Pb})$ Pada Minyak Goreng Sebelum Dan Sesudah Digunakan Oleh Pedagang Gorengan Di Pinggir Jalan R.E Martadinata Kelurahan Tondo Kota Palu', pp. 495-502.

Yani, S. (2011) Pengaruh Proses Penggorengan Terhadap Kandungan Logam Pb dan Cu Pada Minyak yang Dipakai Berulang Kali. Universitas Andalas, Padang.

Yuliono, Y. (2006) Pengaruh Aging Terhadap Sifat Fisis dan Mekanis Paduan Al-Si$\mathrm{Cu}$. Universitas Sanata Dharma Yogyakarta. 